Supplementary Materials for

\title{
Future Antarctic bed topography and its implications for ice sheet dynamics
}

by S. Adhikari, E. Ivins, E. Larour, H. Seroussi and M. Morlighem

December 21, 2013

\section{Introduction}

In this document, we present seven figures that supplement to the main text. Sample results from the benchmark experiments [Ivins and James, 1999] are plotted in Fig. S1. Effects of mesh resolution on solution accuracy are also illustrated. In Figs. S2 and S3, we present examples of the past and future DIHs, respectively. The lone ice loading history considered in our calculations is obtained from Ivins et al. [2013]. As for the future, we have four individual sets of the ice load change predicted by the SeaRISE participating ice sheet models [Bindschadler et al., 2013; Nowicki et al., 2013] under the proxy RCP 8.5 emission scenario.

We show in Figs. S4-S5 the bed uplift predictions for individual future ice loadings, combined with the consideration of a lone spin-up loading history, at years AD 2100 and 2500. Model average solutions for future bed uplift rate and associated standard deviations are shown in Fig. S6. Finally, in Fig. S7, we isolate the contribution of the past and future ice loadings (model average) to the predicted GIA uplifts at year AD 2100. Two independent calculations suggest that the role of the future ice loading dominates the final GIA solutions.

\section{References}

Bindschadler, R., Nowicki, S., Abe-Ouchi, A., Aschwanden, A., Choi, H., Fastook, J., Granzow, G., Greve, R., Gutowski, G., Herzfeld, U., Jackson, C., Johnson, J., Khroulev, C., Levermann, A., Lipscomb, W., Martin, M., Morlighem, M., Parizek, B., Pollard, D., Price, S., Ren, D., Saito, F., Sato, T., Seddik, H., Seroussi, H., Takahashi, F., Walker, R., and Wang, W.: Ice-Sheet Model Sensitivities to Environmental Forcing and Their Use in Projecting Future Sea-Level (The SeaRISE Project), J. Glaciol., 59, 195-224, doi:10.3189/2013JoG12J125, 2013.

Ivins, E. R. and James, T. S.: Simple models for late Holocene and present-day Patagonian glacier fluctuations and predictions of a geodetically detectable isostatic response, Geophys. J. Int., 138, 601-624, doi:10.1046/j.1365-246x.1999.00899.x, 1999.

Ivins, E. R., James, T. S., Wahr, J., O. Schrama, E. J., Landerer, F. W., and Simon, K. M.: 
Antarctic contribution to sea level rise observed by GRACE with improved GIA correction, J. Geophys. Res., 118, 3126-3141, doi:10.1002/jgrb.50208, 2013.

Nowicki, S., Bindschadler, R., Abe-Ouchi, A., Aschwanden, A., Bueler, E., Choi, H., Fastook, J., Granzow, G., Greve, R., Gutowski, G., Herzfeld, U., Jackson, C., Johnson, J., Khroulev, C., Larour, E., Levermann, A., Lipscomb, W., Martin, M., Morlighem, M., Parizek, B., Pollard, D., Price, S., Ren, D., Rignot, E., Saito, F., Sato, T., Seddik, H., Seroussi, H., Takahashi, K., Walker, R., and Wang, W.: Insights into spatial sensitivities of ice mass response to environmental change from the SeaRISE ice sheet modeling project I: Antarctica, J. Geophys. Res., 118, 1-23, doi:10.1002/jgrf.20081, 2013. 

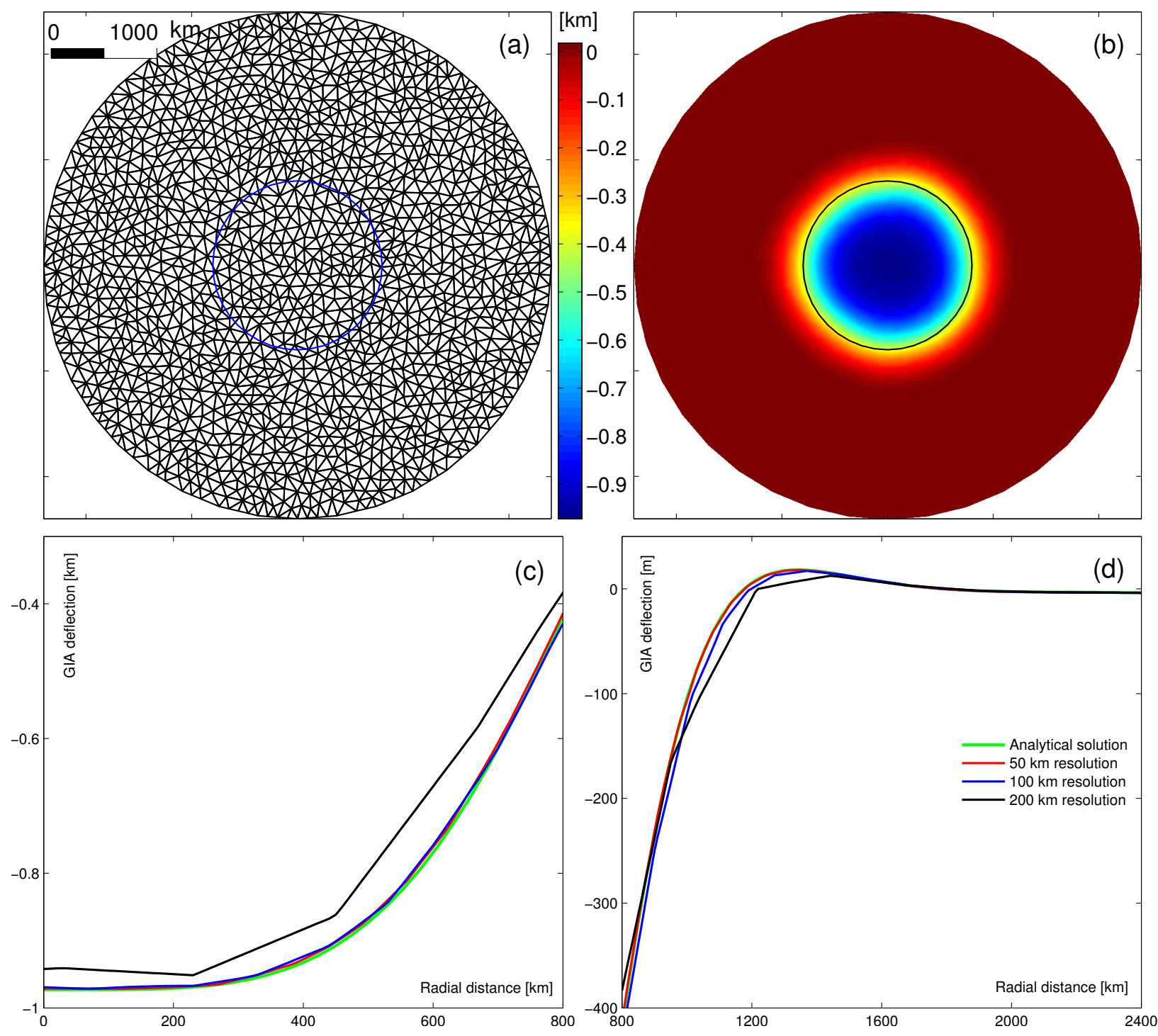

Figure S1: Example benchmark experiment. A round ice sheet, with a radius of $800 \mathrm{~km}$ (notice blue and black circles in (a) and (b), respectively) and a uniform ice thickness of $3 \mathrm{~km}$, rests on the initial flat bed for sufficiently long time so that the steady-state solid Earth response is attained. This resembles one of the benchmark experiments considered by Ivins and James [1999] (see their Fig. A2c). Other parameters include: lithosphere thickness (100 km); material density for ice, lithosphere and mantle $\left(1000,3320\right.$ and $3340 \mathrm{~kg} \mathrm{~m}^{-3}$, respectively); shear modulus of elasticity for lithosphere and mantle (67 and $145 \mathrm{GPa}$, respectively); and mantle viscosity $\left(1 \times 10^{21} \mathrm{Pas}\right)$. (a) The finite-element discretization of the domain including farfield, with maximum element size of $100 \mathrm{~km}$. (b) Corresponding steady-state GIA solution. Effects of mesh resolution on the GIA solutions (c) underneath the ice sheet, and (d) in the farfield. 


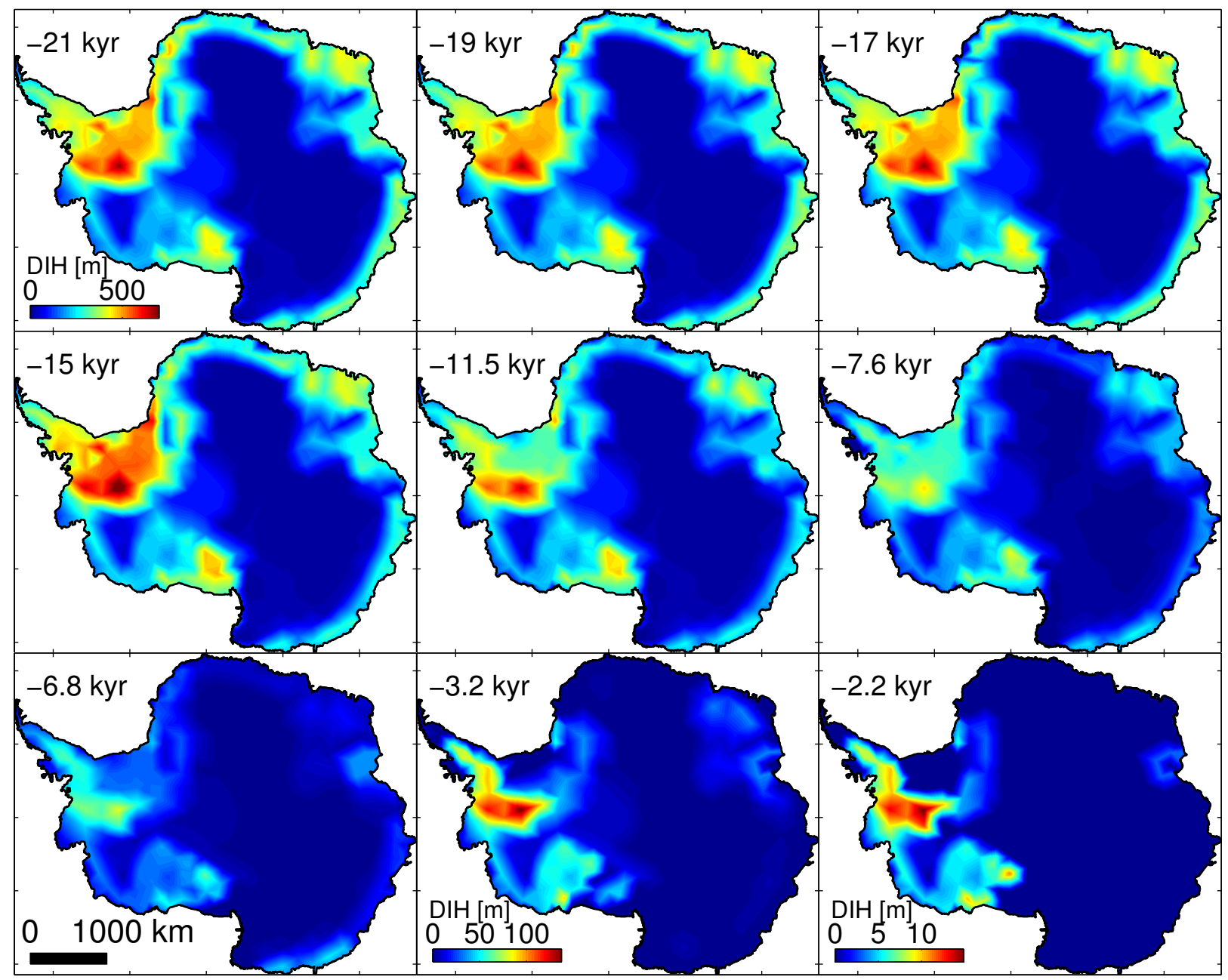

Figure S2: Inferred ice loading history since the LGM. The DIHs, $\Delta h(x, y, t)$ in meters, shown for nine time stamps in the past are obtained from Ivins et al. [2013]. Note that we assume $\Delta h(x, y,-102)=\Delta h(x, y,-1)=0$ meters as explained in the main text. For ease of comparison, same color scale is used except for $t=-3.2$ and $-2.2 \mathrm{kyr}$. 


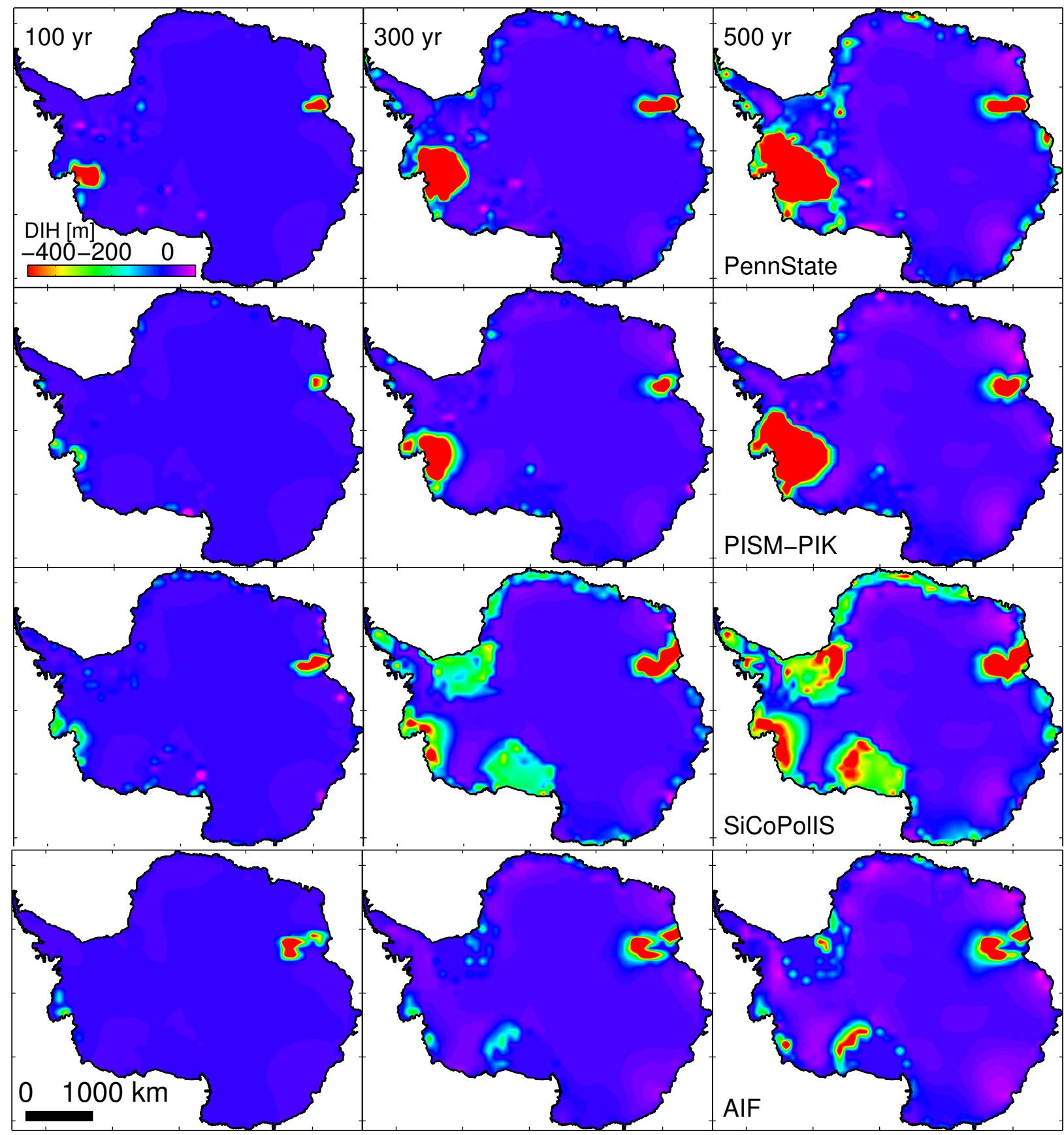

Figure S3: Examples of predicted ice load change for the future. Four rows of the figure respectively depict the future ice loadings obtained from the PennState, PISM-PIK, SiCoPolIS, and AIF ice sheet model simulations. For each model, three columns of the figure respectively depict the DIHs at $t=100,300$ and 500 years. Note that we use the same color scale for ease of comparison. 

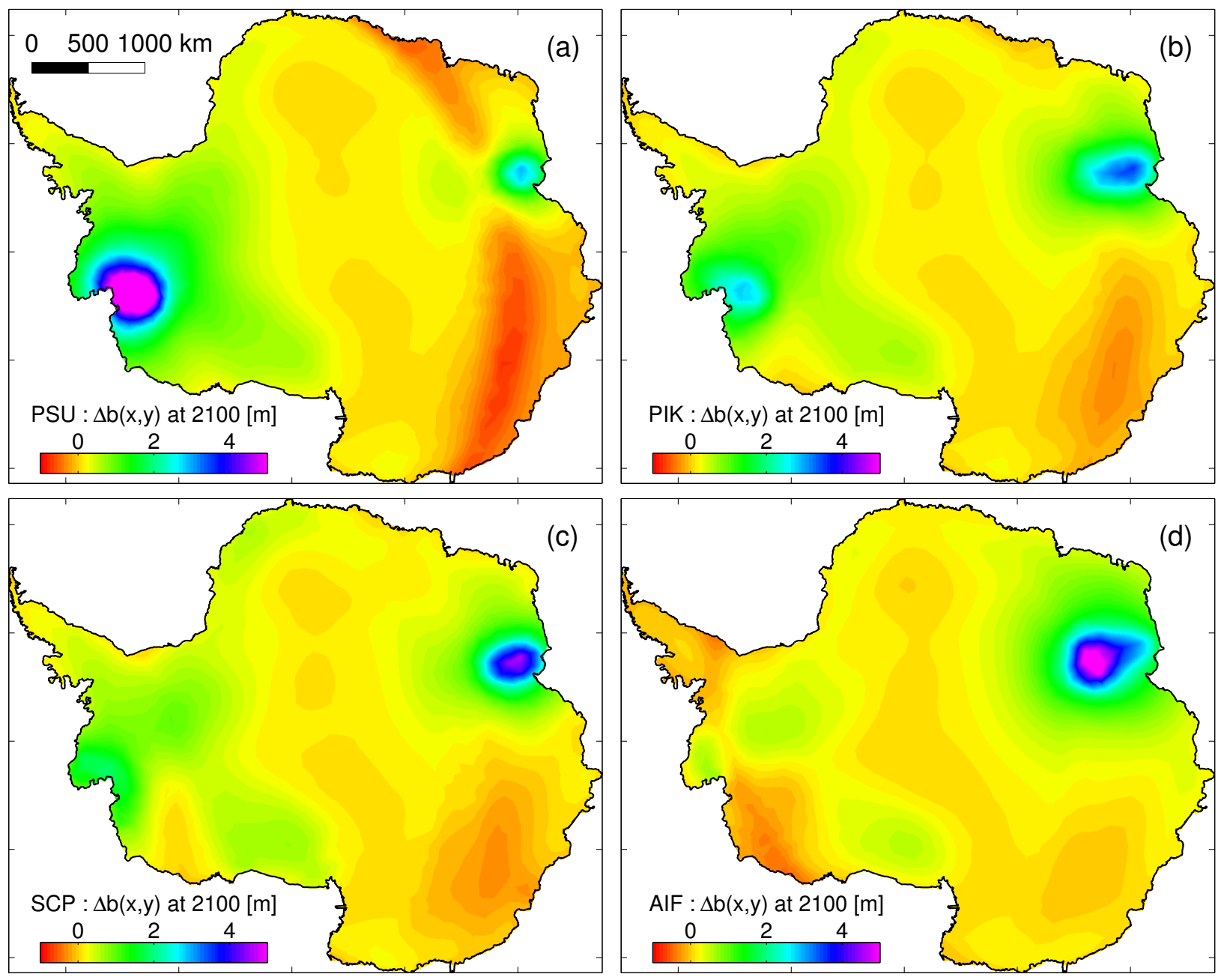

Figure S4: Model predictions for the bed uplift at AD 2100. The GIA solutions associated with the future ice loadings obtained from the (a) PennState, (b) PISM-PIK, (c) SiCoPolIS, and (d) AIF ice sheet models. Same color scale is used for ease of comparison. Note that the model average GIA solutions and the standard deviations are respectively shown in Figs. 3a and 3c (main text). 

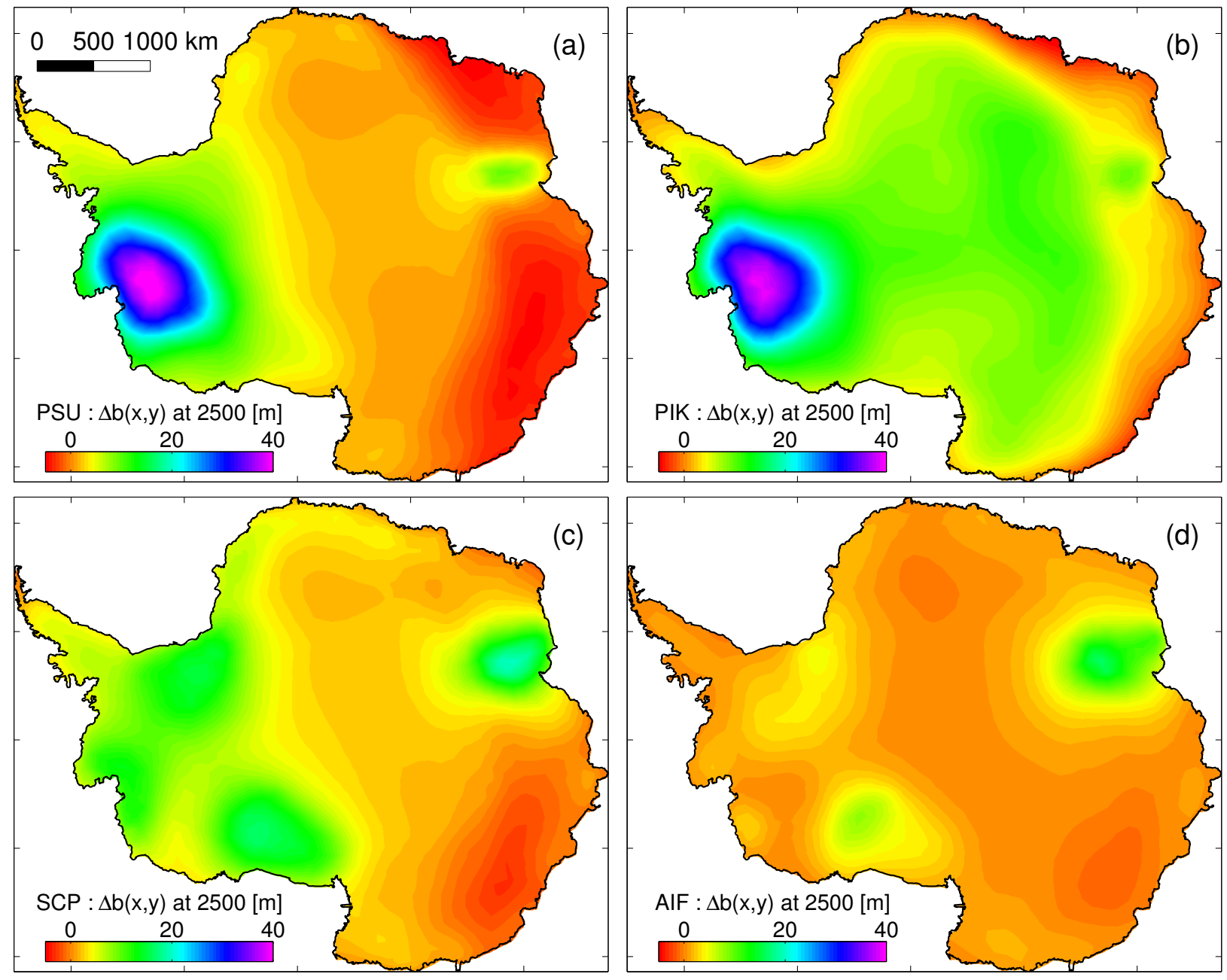

Figure S5: Model predictions for the bed uplift at AD 2500. The GIA solutions associated with the future ice loadings obtained from the (a) PennState, (b) PISM-PIK, (c) SiCoPolIS, and (d) AIF ice sheet models. Same color scale is used for ease of comparison. Note that the model average GIA solutions and the standard deviations are respectively shown in Figs. 3b and 3d (main text). 

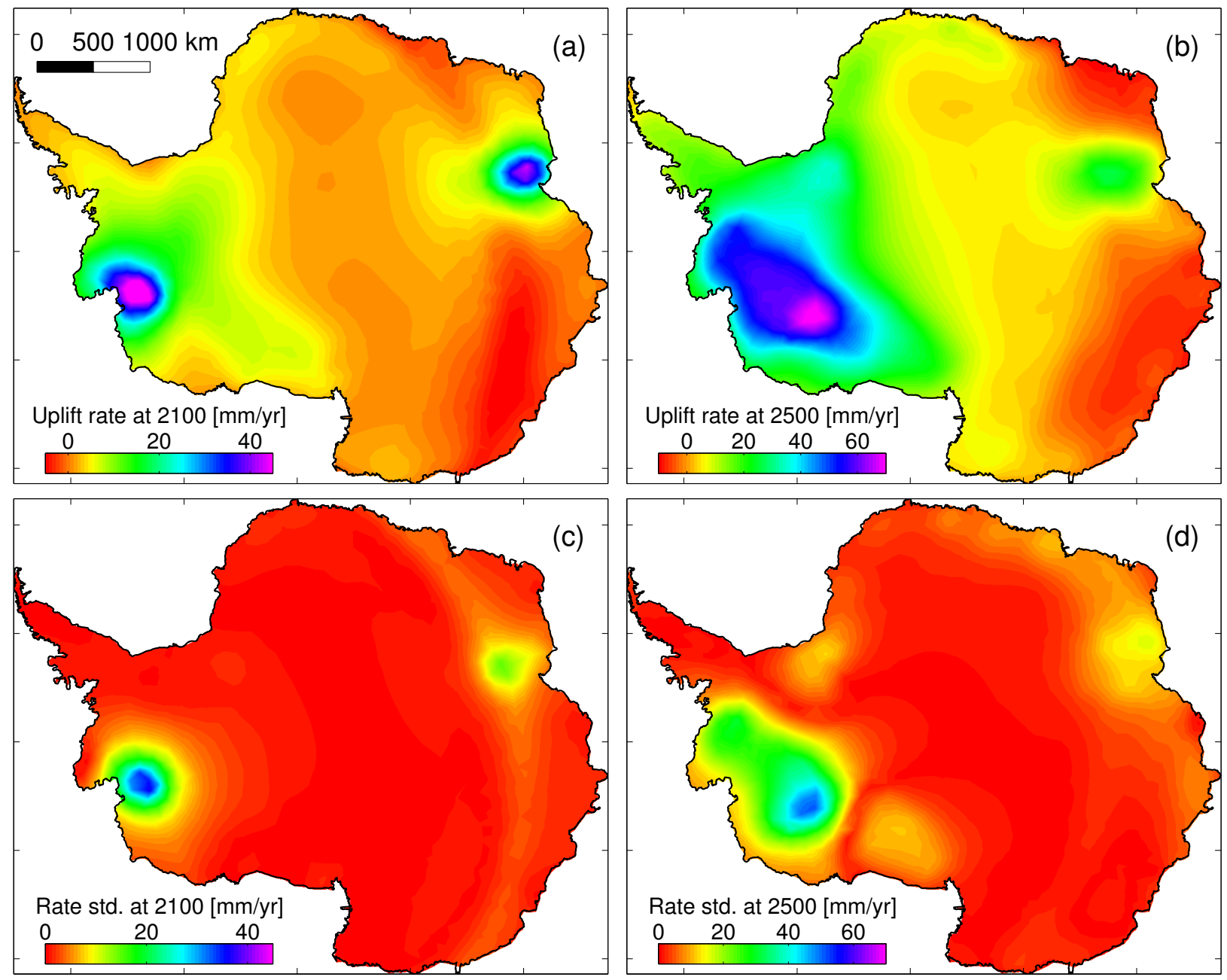

Figure S6: First-order estimates of the future Antarctic bed uplift rate. Average model predictions for bed uplift rate at (a) AD 2100 and (b) AD 2500 under the proxy RCP 8.5 scenario. Associated standard deviations are shown in subplots (c) and (d), respectively. See Fig. 3 of the main text for corresponding solutions for the future bed uplift. 

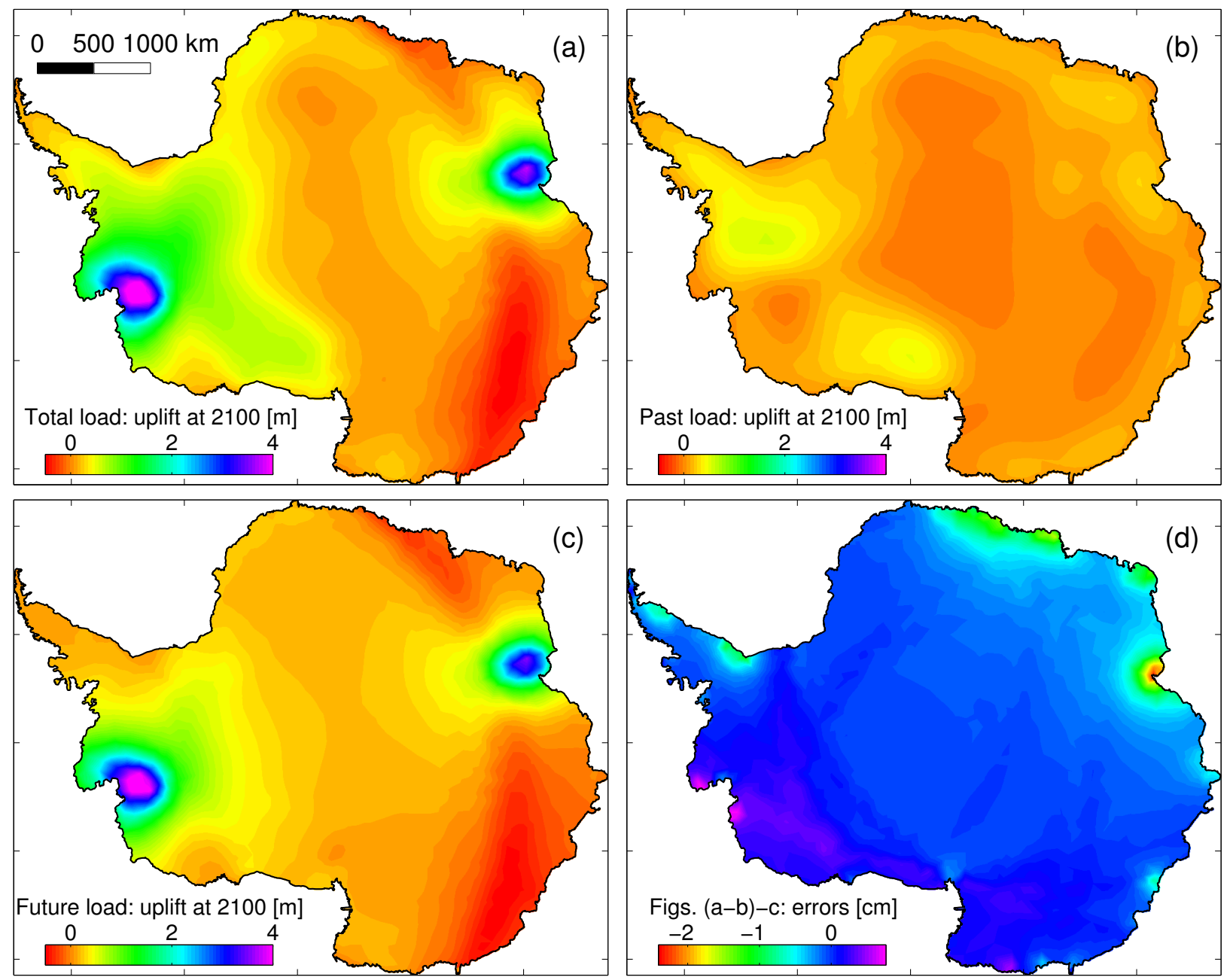

Figure S7: Contribution of the past and future ice loadings to the GIA solutions at AD 2100. (a) Predictions of the GIA uplift obtained by averaging the solutions shown in Fig. S4 (same as Fig. 3a in the main text). (b) GIA solutions due to the past loading alone, assuming that the present-day AIS remains as is in the future. (c) GIA solutions (model average) due to the future ice loading alone, assuming that the past AIS used to have the same configuration as present for sufficiently long time. An alternative solution equivalent to (c) may be obtained by subtracting (b) from (a). Thus obtained solution is essentially the same as shown in (c), implying that the principle of linear superposition holds. (d) Difference between the alternative solution and the one depicted in (c). Note that we use same color scale in (a)-(c) for ease of comparison. 